\title{
Interpreting Interdependence in Fazang's Metaphysics
}

\author{
Nicholaos Jones $^{1}$ iD
}

Received: 22 February 2021 / Revised: 14 September 2021 / Accepted: 24 October 2021 /

Published online: 24 February 2022

(c) The Author(s), under exclusive licence to Springer Nature Switzerland AG 2022

\begin{abstract}
This paper examines the metaphysics of interdependence in the work of the Chinese Buddhist Fazang. The dominant approach of this metaphysics interprets it as a species of metaphysical coherentism wherein everything depends upon everything else, no individual is more fundamental than any other, and so reality itself is nonwell-founded in the sense that chains of dependence never terminate. I argue, to the contrary, that Fazang's metaphysics is better interpreted as a novel variety of foundationalism. I argue, as well, using set- and graph-theoretic techniques, that there is a consistent way to model this alternative interpretation, and that this model differs in significant ways from a coherentist model.
\end{abstract}

Keywords Fazang · Huayan Buddhism · Indra's net · Metaphysical coherentism

\section{Introductory Remarks}

Modern astronomy teaches that the shadow of the night depends upon Earth's surface; modern biology, that animal bodies depend upon their cells, which in turn depend upon organelles. Abrahamic religions teach that contingently existing things depend upon God; philosophical Daoism, that the myriad things (wan wu 萬物) depend upon dao 道. These relations of dependence are metaphysical rather than causal, because that which depends upon another has the other as its simultaneous source, and this source helps to explain its existence and identity. Insofar as no explanandum helps to explain its explanans, metaphysical dependence relations seem to be anti-symmetric, such that no individuals depend upon each other. The anti-symmetry of metaphysical dependence, together with the assumption that all chains of metaphysical dependence terminate, entail metaphysical foundationalism - the view that some individuals depend upon no others. Insofar as some

Nicholaos Jones

nick.jones@uah.edu

1 Department of Philosophy and Political Science, The University of Alabama in Huntsville, Huntsville, AL, USA 
individuals depend upon others for their existence or identity, metaphysical foundationalism is a natural view to hold about the (dependence) structure of reality.

Many philosophers, past and present, European and Asian, endorse some version of metaphysical foundationalism (see Bliss and Priest, 2018a, b). Recent analytic metaphysics, however, exhibits a growing interest in metaphysical coherentism as an alternative to metaphysical foundationalism (see Bliss, 2014; Thompson, 2016; Barnes, 2018; Morganti, 2018). Metaphysical coherentism is a view wherein everything depends upon everything else, no individual is more fundamental than any other, and so reality itself is non-well-founded in the sense that chains of dependence never terminate. Some cite certain state-of-affairs metaphysics and trope metaphysics as evidence for the viability of metaphysical coherentism (see Barnes, 2018, 57-59). Others, however, argue that the paradigmatic metaphysical coherentist comes from the Buddhist tradition, citing the Chinese monk Fazang as an exemplar (see Bliss and Priest, 2018a, b, 71-72; Priest, 2018a, 130-131; Bliss forthcoming).

Fazang 法藏 (643-712) is the third patriarch of the Huayan 華嚴 tradition of Chinese Buddhism. Huayan is one of several indigenously Chinese Buddhist traditions. It is known for teaching that one is all and all is one, as well as for influencing Chan (Zen) Buddhism and Neo-Confucianism (see Van Norden and Jones 2019). Fazang, for his part, is known for systematizing Huayan's metaphysics. Some older scholarship supports interpreting Fazang as a metaphysical coherentist. (Bliss and Priest, for example, tend to cite Chang, 1972 and Cook, 1977). More recent scholarship on Fazang's metaphysics, however, casts some doubt on this interpretation (see Jones, 2015, 142-144; Jones, 2018; 317-319). These doubts, if apt, diminish the historical evidence in favor of metaphysical coherentism as a viable alternative to foundationalism.

I shall argue, in conformity with more recent scholarship, that Fazang endorses a novel species of foundationalism. ${ }^{1}$ Fazang's metaphysics is a species of foundationalism, insofar as it maintains that each dharma is fundamental, a terminus for a chain of dependence. It is a novel species of foundationalism, insofar as the fundamentality of each dharma is aspectual. On the aspectual interpretation I shall defend, Fazang endorses a metaphysics whereby every dharma has two aspectsone whereby all other dharmas depend upon it while it depends upon nothing else, another whereby it depends upon others while nothing depends upon it. I admit that this is a counterintuitive view-and for those who prefer to reserve the category of foundationalism for something more conventional, I have no attachment to the categorization. Setting aside naming preferences, I offer two kinds of support for my interpretation. I argue, first, that Fazang's writings favor the aspectual interpretation

\footnotetext{
1 Some scholars deny that Buddhism, properly understood, engages in metaphysical speculation. (An anonymous referee for this journal raises precisely this concern, arguing that Fazang's views are inconsistent with Buddhist teachings by virtue of being metaphysical.) The intended audience for this paper is the group of scholars who do not frame Buddhist teaching as hostile to metaphysical inquiry. This group includes most contemporary philosophers who engage with Fazang's writings. It includes, as well, those who interpret central Buddhist concepts_-regarding self, causality, and momentariness, among othersas having metaphysical import. Even with this caveat, I shall have occasion to question whether Fazang's views are consistent with the teaching of dependent arising.
} 
over its coherentist alternative. I demonstrate, second, using set- and graph-theoretic techniques, that there is a consistent way to model Fazang's view under an aspectualist interpretation, and that this model differs from a coherentist model.

I begin by introducing Fazang's metaphor of Indra's net as a model for understanding interdependence. Indra's net merits discussion, because coherentist interpreters of Fazang most frequently invoke this metaphor as support for their view. I use Fazang's remarks about the metaphor to cast doubt upon a coherentist interpretation of his view. Because Fazang's remarks about Indra's net are brief, I next attend to some of Fazang's more metaphysical writings in order to defend an interpretation of Fazang's view. I argue that this interpretation qualifies as an aspectual variant of foundationalism, and that it coheres with Fazang's writings better than the coherentist interpretation. I then construct a formal model of Fazang's view (as I interpret it), and I contrast this model with a formal model of its coherentist competitor. I conclude by discussing some potential implications of the aspectual interpretation of interdependence.

\section{Contemplating Indra's Net}

Coherentism and foundationalism are views about the metaphysical structure of reality. This structure relates individuals with respect to their dependencies upon each other. For Fazang, the individuals so related are the basic constituents of what he refers to as the dharma-realm of dependent arising (dharmadhatu pratītyasamutpāda; fajie yuanqu 法界緣起). He refers to this realm as a dharmarealm (dharmadhātu, fajie 法界), because he maintains that the fundamental constituents of reality are dharmas ( $f a$ 法). In his commentary on Devendraprajña's (d. 691) Discourse on the Dharma-Realm's Non-Duality (Dasheng fajie wu chabie lun $s h u$ 大乘法界無差別論疏), Fazang offers a threefold analysis of dharmas:

Dharma has three meanings. The first is that which upholds and maintains, meaning that its self-nature does not change. The second is rule/doctrine, referring to standards that give birth to release [from samsāra]. The third is mental object, referring to what is known to discriminating consciousness. ${ }^{2}$ (T44.1838.63b18-63b19)

Fazang refers to the dharma-realm as a realm of dependent arising (pratītyasamutpāda, yuanqu 緣起), because he affirms the Buddhist teaching of dependent arising whereby every dharma arises in dependence upon other dharmas. Part of Fazang's significance, in the history of (Chinese) Buddhism, is the way in which he articulates this teaching. Fazang maintains not only that each dharma depends upon some other dharma, but also that each depends upon every other dharma. Commentators typically characterize Fazang as endorsing

\footnotetext{
${ }^{2}$ Unless otherwise noted, all translations are my own.
} 
a metaphysics of interdependent arising, using the prefix "inter-" to mark that Fazang's view strengthens the more typical Buddhist metaphysics of dependent arising.

Of the several metaphors Fazang offers for understanding interdependence within the dharma-realm of dependent arising, the metaphor of Indra's net has the most explicit and direct connection to Huayan Buddhism's root scripture, the Avatamsaka Sütra (Huayan Jing 華嚴經). This scripture, in its thirty-third chapter, associates Indra's net with the teaching of dependent arising:

[All Buddhas] know that every dharma ( $\mathrm{fa}$ 法) always obeys dependent arising exhaustively and without exception. They know every kind of world exhaustively and without exception. They know the entire dharma-realm is throughout like Indra's net, and they know the particularity of all the various shi 事 within this net exhaustively and without exception. (T10.279.248.c14-16)

The Avatamsaka Sütra does not elaborate upon this association. But in Contemplations on Exhausting Delusion and Returning to the Source by Cultivating the Mysteries of Huayan (Xui Huayan ao zhi wang jin huan yuan guan 修華嚴奧 旨妄盡還源觀), Fazang offers the following remarks:

The ... contemplation of Indra's net is of chief and attendant manifesting (or revealing) each other. This means that one acting as chief views others acting as attendants; or perhaps one dharma acting as chief [views] all [other] dharmas acting as attendants; or perhaps one body acting as chief [views] all [other] bodies acting as attendants. So one dharma, selected as chief, receives [the other] attendants all together, one after the other without limit. This models the nature of dharmas as manifesting reflections one after another, each shi central to all [others] without limit, just as compassion and wisdom also multiply one after the other without limit. (T45.1876.640b27-640c03)

The intended meaning of Fazang's contemplation of Indra's net is difficult to interpret.

It is natural to interpret Fazang's contemplation as expressing a view known as metaphysical coherentism. Coherentist interpretations of Indra's net are especially prominent with Buddhist approaches to ecology. Here is a typical example:

In Hua-yen Buddhism we find a simile or a legend of Indra's net to show the interdependence [sic] nature of man and ecology.... The universe is a complex web of relations. Human relationships are far more important in the social context. Yet relationships of man with the ecological aspects also play a major role for human existence. Humans also have decisive reciprocal relationships with natural factors. All animate and inanimate things in the nature are relative to each other. They mutually help each other for their longer existence. Each individual human being is interlinked with others, with animals as well as with the ecosphere (Ilangakoon, 2014, 105-106).

Here is another example that more explicitly connects Indra's net with an absence of hierarchy: 
We are merely one node in the endless web of life. From the perspective of Indra's Net, there is no hierarchy among the interdependent things of life (Barnhill, 1990, 21).

This approach to conceptualizing human-nature relationships typically serves to motivate more compassionate and biocentric - and so less instrumentalist and anthropocentric - relationships with the environment. The argument, in brief, is that since nothing in nature is more fundamental than any other, human needs merit no special priority over the needs of other species (see also Cook, 1977, 5-6; Kaza, 1993, 57; Thiele, 2011, 18).

The propriety of interpreting Fazang's contemplation as endorsing a species of metaphysical coherentism is unclear for several reasons. Some are exegetical. For example, insofar as coherentism rejects hierarchies of dependence whereby some individuals are more fundamental than others, why, in the preceding quotation from Contemplations on Exhausting Delusion and Returning to the Source by Cultivating the Mysteries of Huayan, does Fazang speak of some dharmas as chief, others as attendants? Other reasons are theoretical. For example, contemporary metaphysicians typically treat dependence relations among individuals as anti-symmetric. Coherentism entails, however, that some dependence relations are symmetric. The coherentist interpretation of Fazang's contemplation, accordingly, seems to violate a methodological principle of charity enjoining us to prefer interpretations that, by our lights, are more likely true than false (see Williamson, 2005, 220).

\section{Analyzing Fazang's Contemplation}

The central difficulty for interpreting Fazang's contemplation of Indra's net is the relative dearth of specific detail Fazang offers for the content of his contemplation. There are, fortunately, clues to Fazang's meaning in the final chapter of his Treatise on the Five Teachings of Huayan (Huayan Wujiao Zhang 華嚴五教章). The second section of the final chapter analyzes dharmas as dependently arisen causes (yuanqi yin men 緣起因門). This analysis considers dharmas relationally, as causing and being caused by each other. ${ }^{3}$

\footnotetext{
${ }^{3}$ Fazang declares that the analysis of dharmas as dependently arisen causes pertains to the realm of Samantabhadra (Puxian jingjie 普賢境界) (T45.1866.503a19). Those who experience this realm cognize differences and relations among dharmas, and they do so in ways that are free from delusion. He contrasts the realm of Samantabhadra with the realm of Mañjuśrī (Wenshu 文殊). Because the latter realm is inexpressible and inconceivable, those who experience this realm cognize dharmas only as such (or as Suchness, 䢐如 zhenru), without mediation through concepts such as being the cause of or depending upon. Fazang maintains that the realm of Samantabhadra is epistemically prior to the realm of Mañjuśrī, because cognizing the former is a vehicle for cognizing the latter (T45.1866.503a20-25; see also Hamar 2012, 62-63). He also maintains that the realm of Mañjuśrī is ontologically prior to the realm of Samantabhadra, because he conceptualizes dharmas as such as the source of distinct and interdependent dharmas (T45.1866.499b; see also Liu 1979, 361-362.).
} 


\subsection{Analyzing Dharmas as Causes}

Fazang's analysis of dharmas as causes involves two salient posits (see Cook, 1970, 446; Liu, 1979, 396-401). The first is that every dharma simultaneously has the aspect of existing or being present (you 有) and the aspect of absence or being empty (kong 空). As existing, each dharma appears as an individual—a particular with (spatiotemporal) boundaries that suffice well enough to demarcate it from other such particulars and thereby render it countable; and each dharma determines the nature of others. ${ }^{4}$ As empty, each dharma lacks any sort of intrinsic self-nature that would render its nature invulnerable to others. These dual aspects distinguish dharmas from sovereign selves (ätma), which exist but are not empty, and from mere phantasms, which are empty and do not exist. ${ }^{5}$

Fazang's second posit is that every dharma also simultaneously has the aspects of having power (youquanli 有全力) and lacking power (quanwuli 全無力). As powerful, each dharma takes in others, affecting others in ways beyond their control and despite their resistance. As powerless, each dharma is vulnerable to others, entering into them, affected by them in ways beyond its own control and despite its resistance. These dual aspects also distinguish dharmas from sovereign selves (ätma), which are powerful but not powerless, and from mere phantasms, which are powerless but not powerful.

Fazang correlates the existing aspect of dharmas with their aspect of having power, and the empty aspect of dharmas with their aspect of lacking power. The latter correlation receives support from the Discourse on No-Self (Anatta-lakkhana Sutta SN 22.59), which argues that selves are empty because they lend themselves to $d u h k h a$-because they lack power to resist the results of hindrances and defilements (see Harvey, 1995, 47). The former correlation receives support from a principle that contemporary metaphysicians refer to as Alexander's Dictum, according to which power to affect others coincides with, or at least entails, existence (see Cargile, 2003).

Fazang's analyses of dharmas as dual-aspect causes, and the correlations among those aspects, receive support and clarification from the substance-function hermeneutic (see Jones, 2018, 306-313). ${ }^{6}$ This hermeneutic pervades the Chinese

\footnotetext{
4 This account of individual follows Pradeu's except for dropping the requirement that individuals have transtemporal identity. A particular, on Pradeu's account, is "anything that can be designated through a demonstrative reference (this F)." See Pradeu 2010, 247.

5 Although Fazang conceptualizes existing and being empty as contraries, he does not conceptualize existing as ontologically committing. Insofar as dharmas are empty, they exist in the (ontologically committing) sense of being part of the furniture of the dharma-realm. They do not, however, determine the nature of others.

6 The potential influence of indigenous Chinese metaphysics is also worth noting. For example, according to Robin Wang, yinyang metaphysics conceptualizes yin 陰 and yang 陽 as interdependent and mutually inclusive, so that "even something that is strongly yang can be considered yin in some relations" (Wang 2015, 24). For example, Fazang's father has an aspect whereby he is yang, by virtue of being Fazang's superior; but the same person simultaneously has an aspect whereby he is yin, by virtue of being subordinate to the ruler. Conceptualizing things as having the dual aspects of yang and yin is akin to Fazang's conception of dharmas as having the dual aspects of existing and being empty. Whether this
} 
engagement with Buddhism. Chinese Buddhists use the contrast between substance and function as a hermeneutic to avoid tendencies to treat other conceptual pairings—such as form (rūpa, se 色) and emptiness (śūnyatā, kong 空), or knowing wisdom (prajña, zhi hui 智慧) and skillful means (upāya, fang bian 方便)—as exclusionary rather than complementary (see Muller, 2016, 115). The substance-function contrast is, accordingly, said to be nondual:

The purpose of the [substance-function] formula is to show the inseparability of two seemingly separate but in reality nondistinct things.... [T] he purpose of the [substance-function] hermeneutic device in Chinese Buddhist texts is to remove false discriminations originating from a dualistic way of thinking, as reflected in such dichotomies as subject-object, means-end, cause-effect, arising-cessation, and birth-death (Park, 1983, 36).

According to this hermeneutic, substance corresponds to that which is internal and hidden, constitutive of something's identity; and function corresponds to that which is external and visible, a manifestation of something's constitutive identity. For example, with respect to a tree, the substance is the root system, the function the trunk and branches. The contrast between substance and function is nondual, because while the root system is not identical to the trunk and branches, the tree's roots develop together with its trunk and branches (and inseparably so).

Fazang, like many other Chinese Buddhists, endorses the Madhyamikan teaching that all dharmas manifest as empty. He also correlates emptiness with powerlessness. Hence, when interpreted in accordance with the substance-function hermeneutic, Fazang's analysis of dharmas ascribes to each dharma a functional aspect whereby it is empty and lacking power. Fazang further correlates existing with powerfulness. Insofar as substance and function are not identical,the substance-function hermeneutic further indicates that Fazang's analysis ascribes to each dharma a second, substantial aspect whereby it exists and has power.

\subsection{Applying Fazang's Analysis}

Fazang's analysis bears directly upon the contemplation of Indra's net-so much so that his analysis almost yields an interpretation of his contemplation as a corollary. Fazang's contemplation posits that every dharma - every individual within Indra's net—simultaneously has the aspects of being chief ( $z h u$ 主) and being attendant (ban 件). It is natural to interpret the chief-attendant distinction as an instance of the substance-function distinction. This interpretive maneuver does not settle which member of the chief-attendant duality corresponds with which member of the substance-function duality. But Fazang's analysis of dharmas as causes supports interpreting chiefs as substance and attendants as function.

Footnote 6 (continued)

similarity contributes to Fazang's conception of dharmas remains an open question. (For a potentially relevant discussion, see Lai 1980.). 
According to Fazang's analysis, dharmas are substantial insofar as they have power, and having power means affecting others in ways beyond their control and despite their resistance. Chiefs have exactly this power over their attendants. This entails that being chief corresponds to the substance aspect of dharmas. Insofar as the different aspects of dharmas exclude each other, it follows that being attendant corresponds to the function aspect of dharmas.

Combining these correspondences with other correlations from Fazang's analysis of dharmas as causes yields two significant interpretive conclusions. The first is that, insofar as a dharma is chief, it exists and has power. The second is that, insofar as a dharma is an attendant, it is empty and lacks power. These conclusions indicate that Fazang speaks of some dharmas as chief and others as attendants because he maintains that, insofar as dharmas are causes, they are existing and powerful in one aspect, empty and powerless in another. Insofar as every tribe has exactly one chief, these conclusions also indicate that Fazang endorses a sort of aspectualism whereby every dharma by itself has a substantial aspect whereby it enacts the role of chief and another, functional aspect whereby it enacts (with others) the role of attendant.

\subsection{Confirming the Application}

The third section of the final chapter of Fazang's Treatise on the Five Teachings of Huayan provides some confirmation for this interpretation. Three passages from this section are especially salient. The first concerns the relation of identity ( $j i$ 即) among dharmas.

First: Self as existing necessitates the others lacking [existence], so that the others are identical with self. Why? The others lack self-nature, because self creates [them]. Second: Self as empty necessitates the others existing, so that self is identical with the others. Why? Because self lacks self-nature, therefore the others create [it]. (T45.1866.503b10-503b13)

The second concerns the relation of inclusion ( $r u$ 入)—and its converse, "taking in" (she 攝)—among dharmas.

Self having complete power as cause thereby allows it to take in the others. The others completely lacking power as cause thereby allows them to be included within (or enter into) self. Understand by contrast the others having power and self lacking power. (T45.1866.503b16-503b18)

These passages indicate that insofar as one dharma exists or has power, the others are empty and lack power; and that insofar as one dharma is empty or lacking power, the others exist and have power. The passages also indicate that the salient relations among dharmas are one-many (or many-one) relations rather than many-many.

A third passage connects the relations of identity and inclusion with the aspects of substance and function, respectively.

Also, by means of function subsuming substance, and so not being separate from substance, there is nothing more than the mutual inclusion of dharmas. By means of substance subsuming function, and so not being separate 
from function, there is nothing more than the mutual identity of dharmas.

(T45.1866.503b21-503b23)

This passage indicates that Fazang correlates identity among dharmas with their substantial aspect and inclusion among dharmas with their functional aspect. Because Fazang also correlates identity among dharmas with the aspects of existing and being empty, and inclusion among dharmas with the aspects of having power and lacking power, it follows that dharmas are substantial insofar as they exist and have power, functional insofar as they are empty and lack power.

\section{Deciding among Interpretations}

The preceding interpretation for Fazang's contemplation of Indra's net entails that Fazang does not endorse metaphysical coherentism. Fazang endorses aspectual hierarchies among dharmas. Every dharma has an aspect whereby it enacts the role of chief and all others enact the role of attendant. But chiefs are more fundamental than attendants, because chiefs are not empty and vulnerable in the way attendants are. Hence, on Fazang's account, every dharma has an aspect whereby it is more fundamental than all other dharmas. Coherentism, however, entails that dharmas are always and only attendants, because it requires dharmas to arise in dependence upon all others and thereby precludes any one dharma from creating another without assistance from others. Because coherentism rejects any hierarchy of dependence whereby some individual, acting as chief, is more fundamental than others, Fazang's contemplation of Indra's net is not coherentist.

The standard alternative to metaphysical coherentism is metaphysical foundationalism. According to metaphysical foundationalism, there are hierarchies of dependence, and these hierarchies bottom out in some individual, or some collection of individuals, for which nothing is more fundamental. Fazang endorses aspectual hierarchies, and he maintains that each hierarchy bottoms out in some dharma that, in one aspect, is more fundamental than any other dharma. So Fazang's contemplation of Indra's net seems to be a sort of foundationalism—albeit an unusual, aspectual sort.

Regardless of whether foundationalism admits aspectual variants, Fazang's contemplation, according to the preceding interpretation, has the virtue of honoring the contemporary tendency to treat dependence as an anti-symmetric relation. Dharmas as attendants are empty and thereby depend upon another. Dharmas as chiefs are not empty and thereby do not depend upon others. Because Fazang maintains that the status of any dharma as chief or attendant is aspectual, and because he denies that there is any aspect whereby a dharma simultaneously enacts the roles of chief and attendant, Fazang's contemplation entails that, for any dharma, the aspect in which it (as attendant) depends upon another never coincides with the aspect in which others depend on it (as chief).

It remains unclear whether the preceding interpretation of Fazang's contemplation honors a principle of charity enjoining us to prefer interpretations that are, by our lights, more likely true than false. The interpretation ascribes to Fazang a sort of aspectualism, whereby every dharma has two distinct aspects. Aspectualism is 
not, at present, a mainstream metaphysical view. But the view has received some contemporary attention (Baxter, 2018; Turner, 2014). So Fazang's contemplation provides some reason to reconsider more familiar approaches to conceptualizing the metaphysical structure of reality.

Despite these qualifications, one might object that interpreting Fazang's view as some kind of aspectualism is inconsistent with the Huayan doctrine that all things lack obstruction (shishi wu ai 事事無礙). This doctrine expresses, for the dharmarealm of dependent arising, a teaching from the Avatamsaka Sütra according to which "all things are nondual, beyond duality, all equal...not distinguishing self and nonself" (Cleary 1993, 1011). There is, however, precedent for conceptualizing equality as opposed to hierarchy (see Olds, 1992, 409; Wang, 2005, 225). Hence, insofar as Fazang endorses the equality of dharmas, and insofar as equality precludes hierarchies of dependency, the interdependence of dharmas is inconsistent with supposing that each dharma has an aspect whereby it is more (or less) fundamental than others and so Fazang's view is better interpreted as a kind of coherentism. ${ }^{7}$

The preceding objection errs in supposing that equality precludes hierarchies of dependence whereby some dharmas are more fundamental than others. On Fazang's view, all dharmas are equal because each has the dual aspects of existing with power and being empty without power. These aspects are nondual, because no dharma has one aspect without also having the other. Moreover, dharmas do not obstruct each other, because one dharma having one aspect does not preclude other dharmas from also having that same aspect. But this does not preclude hierarchical relations of fundamentality among dharmas, because the aspect of one dharma whereby it exists with power correlates with the aspect of other dharmas whereby they are empty without power, and the aspect of one dharma whereby it is empty without power correlates with the aspect of other dharmas whereby they exist with power. If dharmas were to have one aspect but not the other, hierarchical relations of fundamentality among dharmas would preclude their equality. But Fazang is quite explicit that dharmas do not have one aspect to the exclusion of the other. This distinguishes his view from more traditional kinds of foundationalism. Similarly, if the aspects of dharmas were identical to each other, equality among dharmas would preclude hierarchical relations of fundamentality. But Fazang is also quite explicit that the aspect whereby a dharma exists with power is distinct from the aspect whereby it is empty without power. This distinguishes his view from coherentism. Ascribing two aspects to each dharma allows Fazang to accommodate the teaching that dharmas are equal. Correlating these aspects in the way he does also allows Fazang to conceptualize dharmas as more or less fundamental than each other.

\footnotetext{
7 I thank an anonymous referee for this journal for raising this objection.
} 


\section{Modeling the Interpretations}

Fazang's contemplation of Indra's net secures interdependence among dharmas through a sort of aspectualism. Each dharma, in Fazang's contemplation, has one aspect of existing and having power whereby it "takes in" (she 攝) all other dharmas. This is the sense in which each dharma is more fundamental than others and acts as a chief to those others. Each dharma, in Fazang's contemplation, also has another aspect of being empty and lacking power whereby it "enters into" ( $r u$ 入) other dharmas as those others enact their own power. This is the sense in which each dharma is less fundamental than others and acts as an attendant to those others. Contemplating every dharma as having these dual aspects thereby models each dharma as depending upon all other dharmas.

For the sake of forestalling a concern that this aspectual interpretation of Fazang's metaphysics is incoherent or not substantially different from the coherentist interpretation, I use a formal modeling technique to demonstrate salient differences among the interpretations. I follow Priest's strategy of providing set-theoretic models for each interpretation (Priest, 2009, 474-474; Priest, 2018b, 117-120).

Priest offers a set-theoretic model for the coherentist interpretation of interdependent arising. The model posits a non-empty set of objects $X_{0}$ and a set of binary relations $\rho$ among these objects. Priest supposes that, for any distinct objects $x$ and $y$ in $X_{0}$, there is a relation instance $R_{i}$ in $\rho$ that extends from $x$ to $y$. Priest denies that the sets $X_{0}$ and $\rho$ suffice as a model of interdependent arising. His reasons are twofold. First, he maintains that each object $x$ in $X_{0}$ has an intrinsic self-nature. Second, he maintains that each $R_{i}$ in $\rho$ also has an intrinsic self-nature. Insofar as nothing in a model for interdependent arising should have an intrinsic self-nature, it follows that the members of $X_{0}$ and $\rho$ are inappropriate for such a model. Priest thereby refines his model. For example, for each object $x$ in $X_{0}$, he defines the locus of $x$ as the set of relation instances of $\rho$ that extend from $x$ to some object $y$ in $X_{0}$. The locus of each object in $X_{0}$, so defined, is nothing more than a location in a field of relations. Priest takes these loci, rather than the objects and relations from which they are constructed, as models of interdependent dharmas. (Priest, 2009 pursues a similar strategy for the instances of $\rho$, defining a correlate for each that is also nothing more than a location in a field of relations. Priest takes these correlates to be models of relations among interdependent dharmas.)

Priest's justification for supposing that the members of $X_{0}$ and $\rho$ have intrinsic self-natures depends upon his notion of relational existence. Something has relational existence, according to Priest, if and only if there is nothing more to its existence than bearing certain relations to others (Priest, 2009, 467-468). Priest interprets the doctrine of interdependent arising as the view that all dharmas have relational existence. His reasoning, in brief, seems to invoke two premises: first, that interdependently arising dharmas lack intrinsic self-nature; second, that whatever lacks intrinsic self-nature is nothing more than a locus in a field of relations. He argues, as a corollary, that the members of $X_{0}$ and $\rho$ lack relational existence. He justifies the corollary by example. 
Priest's example involves a model with three objects $a, b, c$ and two relations between them, such that $X_{0}=\{a, b, c\}$ and $\rho=\left\{R_{0}, R_{1}\right\}$, and such that $a$ bears $R_{1}$ to $b$ and $R_{0}$ to $c, b$ bears $R_{0}$ to $a$, and $c$ bears $R_{1}$ to itself $(2009,473)$. He represents this model as a directed graph, where superscripted arrows denote relations from $\rho$. (See Fig. 1.)

Priest offers a terse justification for why the constituents of this model-the members of $X_{0}$ and $\rho$-lack relational existence. The justification focuses on the relations rather than the objects:

Each $R_{i}$ [in $\rho$ ] has a collection of instances, $\left\langle R_{i}>\right.$. The standard way to think of these is as sets of ordered pairs - or, actually, ordered triples, the third member indexing the relation. Thus...the members of $\left\langle R_{0}\right\rangle$ would be $\langle b, a, 0\rangle$ and $\langle a$, $c, 0\rangle$, and those of $\left\langle R_{1}\right\rangle$ would be $\langle a, b, 1\rangle$ and $\langle c, c, 1\rangle$. This, of course, is already to think of the objects in $X_{0}$ as existing in themselves $(2009,473)$.

Priest's justification strikes me as incomplete. Nothing in set theory forbids stipulating that the objects in $X_{0}$ lack intrinsic self-natures, nor that they have relational existence. The axioms of, say, Zermelo-Fraenkel set theory concern relations of numerical identity, set membership, and implication among variables of an arbitrary domain. They do not, however, impose restrictions upon the nature of those variables. Moreover, relations are relations among variables. These variables lack relational existence only insofar as they are independent variables. But nothing in Priest's model requires supposing that the objects in $X_{0}$ are independent variables.

I suspect that Priest's aim in constructing a set-theoretic model of interdependent arising is to model, rather than stipulate, the way in which interdependent dharmas lack intrinsic self-natures. Achieving this aim requires constructing a model that exhibits its constituent objects as interdependent. Priest's contention that interdependent dharmas have relational existence then motivates the particular construction he pursues. However, the aspectual interpretation I favor for Fazang's doctrine of interdependent arising denies that dharmas have relational existence. On the aspectual interpretation,

Fig. 1 Priest's graph-theoretic approach to modeling objects and relations. (Created by author in Microsoft PowerPoint. Adapted from Priest, 2009, 431, Fig. 1.)

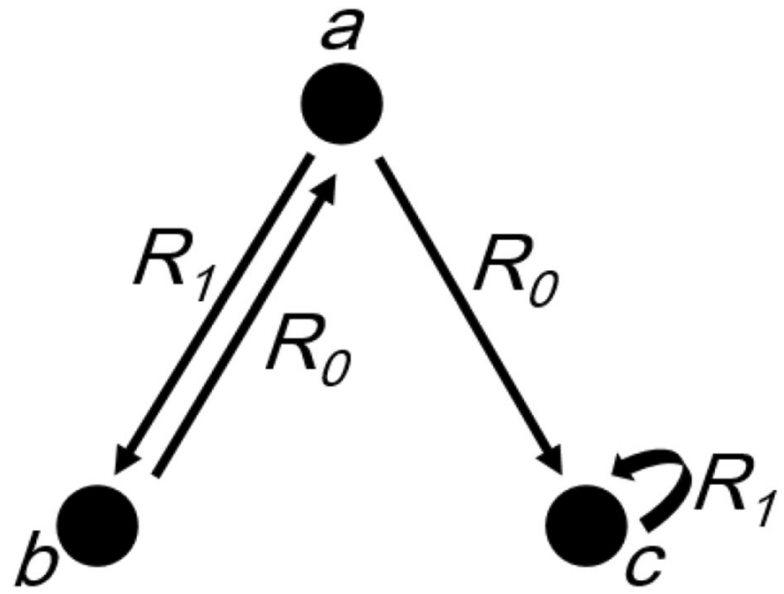


Fig. 2 Transparency sheet wherein objects $b$ and $c$ depend upon object $a$. The filled circle represents an existing object; the open circles, objects that are empty. Directed arrows represent relations whereby the object at the head depends upon the object at the tail. (Created by author in Microsoft PowerPoint.)

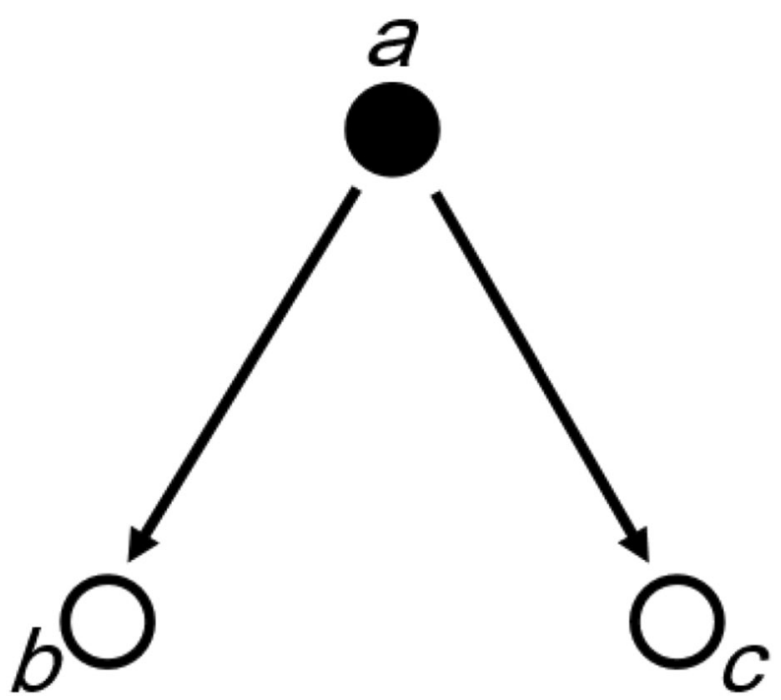

each dharma has an aspect whereby it is empty (and thereby lacking intrinsic selfnature) but also another aspect whereby it exists. Because no dharma, insofar as it exists, depends upon any other dharma, every dharma has an aspect whereby it lacks relational existence. I propose, accordingly, to model the contrast between aspectual and coherentist interpretation of Fazang's doctrine by positing a non-empty set of objects $X_{1}$ such that the members of $X_{1}$ lack intrinsic self-nature.

I conceptualize each object in $X_{1}$ as having one aspect whereby it exists and another aspect whereby it is empty (of intrinsic self-nature). Each object in $X_{1}$ thereby corresponds to a dharma in the dharma-realm of dependent arising as Fazang understands it. I also posit a relation $\delta$ such that $x_{i}$ in $X_{1}$ bears $\delta$ toward $x_{j}$ in $X_{1}$ if and only if $x_{i}$ depends upon $x_{j}$. For the sake of modeling the dual aspects of each object in $X_{1}$, I posit a set of "sheets" $\Sigma$ such that, for each object $x_{i}$ in $X_{1}$, there is one and only one sheet $\sigma_{i}$ in $\Sigma$, where $x_{i}$ is said to ground the sheet. Each sheet corresponds to the aspect of its grounding object whereby the object exists. Each sheet $\sigma_{i}$ in $\Sigma$, grounded in $x_{i}$ from $X_{1}$, consists of a set of objects from $X_{1}$ and a set of relation instances from $\delta$ such that, for all $x_{j} \neq x_{i}$ in $X 1, \delta\left(x_{j}, x_{i}\right), \neg \delta\left(x_{i}, x_{j}\right)$, and for any $x_{k} \neq x_{i}$ in $X_{l}, \neg \delta\left(x_{j}, x_{k}\right)$. That is, each sheet is such that all of its non-grounding objects depend upon its grounding object and there are no other relations of dependence. Insofar as the non-grounding objects for each sheet depend upon the sheet's grounding object, they are empty of intrinsic self-nature. Because, for every object in $X_{1}$, there is one sheet in which it is a grounding object and another (in fact many) in which it is a non-grounding object, it follows that every object in $X_{1}$ has an aspect whereby it exists and another whereby it is empty.

I find it useful to visualize the aspectual model of interdependent arising as a stack of marked transparency sheets. Transparency sheets are an old technology. Each is a transparent page, made of flexible material, onto which figures can be drawn. When placed on an overhead projector, the projector displays the drawing without interference from the sheet. Each transparency sheet corresponds to a sheet 

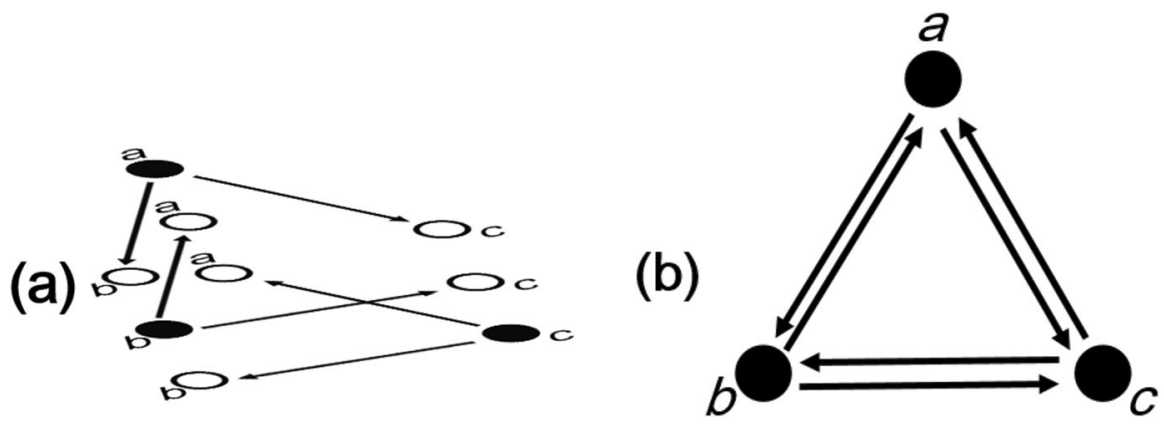

Fig. 3 a A stack of three transparency sheets, each with one existing object and two empty ones. b A projection of the three sheets. (Created by author in Microsoft PowerPoint.)

from $\Sigma$, and the markings on a transparency sheet correspond to a directed graph drawn according to the following instructions: each object in $X_{1}$ receives a "dot" on the transparency sheet, and each relation instance from $\delta$ for a sheet receives an "arrow" drawn from the dot for the sheet's grounding object to the dot for one of the sheet's non-grounding objects. If $X_{1}=\{a, b, c\}$, the transparency for sheet $\sigma_{a}$ would be drawn as a directed graph. (See Fig. 2.)

If one were to stack the transparency sheets drawn for sheets $\sigma_{a}, \sigma_{b}$, and $\sigma_{c}$ one on top of the other and project the stack through an overhead projector, the projection would depict an image wherein there is an "arrow" between each "dot" and every other. (See Fig. 3.)

Interpreting the "dots" as dharmas and the arrows as relations of dependence, the result is an image depicting interdependence among the dharmas (Fig. 3b). The basis for the image - the stack of transparency sheets (Fig. 3a) - then depicts Fazang's model of interdependence in the dharma-realm of dependent arising, with each transparency sheet depicting an aspect of the dharma-realm whereby one dharma exists and the others are empty.

Consider, by contrast to this aspectual model of interdependent arising, a coherentist model. Like the aspectual model, this model contains the set of objects $X_{1}$ and the relation $\delta$. Unlike the aspectual model, this model contains only one sheet $\sigma$ in $\Sigma$, such that $\delta\left(x_{j}, x_{i}\right)$ for all $x_{i}$ and $x_{j}$ in $X_{1}$. (Or, if $\delta$ is neither reflexive nor transitive, $\sigma$ is such that $\delta\left(x_{j}, x_{i}\right)$ for any distinct $x_{i}$ and $x_{j}$ in $X_{l}$. ) Visualizing this model with transparency sheets involves one transparency sheet marked with "dots" for each object and "arrows" for each instance of $\sigma$. The markings that result exactly trace the image projected by the stack of transparency sheets associated with the aspectual model of interdependent arising (Fig. 3b). The central difference between this model and its aspectualist competitor is that the aspectual model represents, in a way the coherentist model does not, Fazang's contention that every dharma has two aspects.

There is a way to articulate this difference formally using Bayesian networks. A Bayesian network consists of a directed graph and a probability distribution. On the aspectual interpretation of interdependence, the dharma-realm is a "stack" of Bayesian networks; on the coherentist interpretation, it is just one network. On both interpretations, the graph for a network is the graph specified by the sheet for a network 
(and depicted on the associated transparency sheet); and the probability distribution for each network is as follows. Each object has a (prior) probability for arising equal to $p$. Each has a (prior) probability for not arising equal to $q=1-p$. Further, objects $x_{i}$ and $x_{j}$ in $X_{1}$ are such that the conditional probability of $x_{i}$ given $x_{j}$ equals 1 whenever $x_{i}$ depends upon $x_{j}$. Given these distributions, it is straightforward to prove that each network is such that all of its objects have the same (prior) probability, and that this probability is greater than 0 and less than 1 . It is also straightforward to prove that the aspectual model, but not the coherentist one, allows some (non-grounding) objects to be (marginally) independent of each other and to be such that the probability of one given the other is less than 1 . So the aspectual interpretation I favor differs from the coherentist interpretation in the sort of (probabilistic) independencies and the values for conditional probabilities it permits.

\section{Concluding Remarks}

Aspectualism and coherentism offer competing interpretations of interdependence. Because the differences among these interpretations are subtle, consider an analogy that likens dharmas to colors. For the sake of simplicity, suppose that there are exactly six color categories: blue, cyan, green, magenta, red, and yellow. Then, just as one might inquire into relations of metaphysical dependence among dharmas, one might inquire into relations of color dependence among these categories. Central to such an inquiry is the question: Which, if any, of the colors are primary, existing independently of other colors; and which are secondary, existing in dependence on primary colors as mixtures of those colors? One answer to this question models red, green, and blue as primary colors, cyan as a mixture of green and blue, magenta as a mixture of blue and red, and yellow as a mixture of red and green (see Pridmore, 1991, 123). A different answer to the same question models cyan, magenta, and yellow as primary colors, blue as a mixture of magenta and cyan, green as a mixture of cyan and yellow, and red as a mixture of yellow and magenta (see Pridmore, 1991, 122). A foundationalist interpretation of color dependency allows at most one of these models to be correct. By contrast, a coherentist interpretation rejects both models in favor of an alternative whereby no color is primary and, instead, each color is a mixture of others.

Like the coherentist interpretation of color dependency, an aspectual interpretation maintains that each color is a mixture of other colors. However, unlike the coherentist interpretation, the aspectual interpretation also maintains that each color is primary. Rather than reject the models of color dependency that treat three colors as primary and three others as secondary, the aspectual interpretation of color dependency maintains that both models are correct by virtue of identifying different aspects of each color. For example, the aspectual interpretation maintains that there is one aspect of red wherein it is primary, another aspect of red whereby it is a mixture of yellow and magenta. Aspectualism about color dependency thereby rejects the foundationalist presupposition that at most one model of color dependency is correct, and it also rejects the coherentist contention that there are no primary colors. By analogy, aspectualism about metaphysical 
dependence rejects the foundationalist presupposition that there is exactly one privileged class of fundamental dharmas, and it rejects the coherentist contention that no dharma is more fundamental than any other. Each dharma has one aspect whereby, as chief, it is more fundamental than other dharmas. Each also has another aspect whereby, as attendant, it depends upon other dharmas.

I have argued that the aspectual interpretation of interdependence better fits Fazang's views about interdependent arising within the realm of dharmas. Because Fazang ascribes to dharmas the dual roles of chief and attendant, his conception of interdependence involves a sort of hierarchy that is consistent with aspectualism but not coherentism. The aspectual interpretation also preserves the anti-symmetry of the dependence relation, while the coherentist interpretion does not. These considerations undermine the contention that Fazang's metaphysics provides a viable example of metaphysical coherentism.

I have provided, as well, a set-theoretic model (and graphical illustration) for the aspectual interpretation. The model formalizes some key differences between the aspectual interpretation and its coherentist competitor. It also allays the concern that the aspectual interpretation is incoherent, by demonstrating that the interpretation supports a self-consistent model of metaphysical reality. Because contemporary discussions of metaphysical foundationalism tend not to consider aspectual variations, this expands the conceptual space for metaphysical inquiry.

A central task for the history of philosophy is to facilitate thinking differently about problems of enduring philosophical relevance (see Antognazza, 2015). The aspectual interpretation for Fazang's contemplation of Indra's net achieves this objective. It provides a view about the structure of reality that combines the hierarchical dependencies of foundationalism with the equalized statuses of coherentism, albeit without collapsing to either of these more familiar alternatives. The apparent dichotomy between hierarchy and equality drives many long-standing debates, including debates about the relations between yang and yin, ruler and subject, man and woman, cause and condition. The aspectual interpretation of Fazang's contemplation thereby reveals an approach to resolving these debates without prioritizing hierarchy over equality or equality over hierarchy.

Data Availability Not applicable.

Code Availability Not applicable.

\section{Declarations}

Conflicts of Interest None.

\section{References}

Antognazza, M. R. (2015). The Benefit to Philosophy of the Study of Its History. British Journal for the History of Philosophy, 23(1), 161-184. https://doi.org/10.1080/09608788.2014.974020 
Barnes, Elizabeth. (2018). Symmetric Dependence. In Ricki Bliss and Graham Priest (Eds.), Reality and Its Structure: Essays in Fundamentality (pp. 50-69) New York: Oxford University Press. https://doi. org/10.1093/oso/9780198755630.003.0003

Barnhill, David L. (1990). Indra's Net as Food Chain: Gary Snyder's Ecological Vision. Ten Directions, $11,20-29$.

Baxter, D. L. M. (2018). Self-Differing, Aspects, and Leibniz's Law. Nous, 52(4), 900-920. https://doi. org/10.1111/nous.12199

Bliss, Ricki. Forthcoming. Some Work for a Theory of Grounding? In Magali Roques (Ed.), Grounding in Medieval Philosophy. Boston: Brill.

Bliss, R. L. (2014). Viciousness and the Structure of Reality. Philosophical Studies, 166(2), 399-418. https://doi.org/10.1007/s11098-012-0043-0

Metaphysical Dependence, East and West. In Steven M. Emmanuel (Ed.), Buddhist Philosophy: A Comparative Approach (pp. 63-85). Malden, MA: John Wily \& Sons. https://doi.org/10.1002/97811 19424246.ch4

Cargile, J. (2003). On “Alexander's” Dictum. Topoi, 22, 143-149. https://doi.org/10.1023/A:1024926205 716

Chang, G. C. C. (1972). The Buddhist Teaching of Totality: The Philosophy of Hwa Yen Buddhism. George Allen \& Unwin Ltd.

Chou, P. (2003). Wŏnhyo's View of the Huayan Doctrine. International Journal of Buddhist Thought \& Culture, 2, 109-122.

Cleary, T., \& (trans.). (1993). The Flower Ornament Scripture: A Translation of The Avatamsaka Sutra. Shambhala.

Cook, Francis H. (1970). Fa-tsang's Treatise on the Five Doctrines: An Annotated Translation. Ph.D. Dissertation, University of Wisconsin.

Cook, F. H. (1977). Hua-yen Buddhism: The Jewel Net of Indra. The Pennsylvania State University Press.

Hamar, I. (2012). Deconstructing and Reconstructing Yogācāra: Ten Levels of Consciousness-Only/One Mind in Huayan Buddhism. In R. Gimello, F. Girard, \& I. Hamar (Eds.), Avatamsaka (Huayan, Kegon, Flower Ornament) Buddhism in East Asia: Origins and Adaptation of a Visual Culture (pp. 53-71). Harrassowitz.

Harvey, P. (1995). The Selfless Mind: Personality, Consciousness and Nirvāna in Early Buddhism. RoutledgeCurzon.

Ilangakoon, Samantha. (2014). Buddhist Religious Ecological Concepts. In Thich Nhat Tu and Thich Duc Thien (Eds.), Buddhist Response to Environmental Protection, Vietnam Buddhist University Series 22 (pp. 99-107). Hanoi: Religion Press.

Jones, Nicholaos. (2015). Buddhist Reductionism and Emptiness in Huayan Perspective. In Koji Tanaka, Yasuo Deguchi, Jay L. Garfield, and Graham Priest (Eds.), The Moon Points Back (pp. 128-149). New York: Oxford University Press. https://doi.org/10.1093/acprof:oso/9780190226862.003.0006

Jones, Nicholaos. (2018). The Metaphysics of Identity in Fazang's Huayan Wujiao Zhang: The Inexhaustible Freedom of Dependent Origination. In Youru Wang and Sandra A. Wawrytko (Eds.), Dao Companion to Chinese Buddhist Philosophy (pp. 295-323). Dordrecht: Springer. https://doi.org/10. 1007/978-90-481-2939-3_13

Kaza, S. (1993). Acting with Compassion: Buddhism, Feminism, and the Environmental Crisis. In C. Adams (Ed.), Ecofeminism and the Sacred (pp. 50-69). Continuum Press.

Lai, W. (1980). The I-Ching and the Formation of the Hua-yen Philosophy. Journal of Chinese Philosophy, 7(3), 245-258.

Liu, Ming-wood. (1979). The Teaching of Fa-tsang: An Examination of Buddhist Metaphysics. Ph.D. Dissertation: University of California, Los Angeles.

Morganti, Matteo. (2018). The Structure of Physical Reality: Beyond Foundationalism. In Ricki Bliss and Graham Priest (Eds.), Reality and Its Structure: Essays in Fundamentality (pp. 254-272). New York: Oxford University Press. https://doi.org/10.1093/oso/9780198755630.003.0014

Muller, A. C. (2016). The Emergence of Essence-Function (ti-yong) 體用 Hermeneutics in the Sinification of Indic Buddhism: An Overview. Bulgyohaglibyu 불 교 학 리뷰 [critical Review for Buddhist Studies], 19, 111-152.

Muller, A. C. (1995). The Key Operative Concepts in Korean Buddhist Syncretic Philosophy; Interpenetration and Essence-Function in Wŏnhyo, Chinul and Kihwa. Tōyō Gakuen Daigaku Kiyō 東洋学 園大学紀要 [bulletin of Tōyō Gakuen University], 3, 33-48.

Olds, L. E. (1992). Integrating Ontological Metaphors: Hierarchy and Interrelatedness. Soundings, 75(23), 403-420. 
Park, S. B. (1983). Buddhist Faith and Sudden Enlightenment. State University of New York Press.

Pradeu, T. (2010). What is an Organism? An Immunological Answer. History and Philosophy of the Life Sciences, 32(2-3), 247-268.

Pridmore, Ralph W. (1991). Theory of Primary Colors and Invariant Hues. Color: Research and Application, $16(2), 122-129$.

Priest, G. (2009). The Structure of Emptiness. Philosophy East and West, 59(4), 467-480. https://doi.org/ 10.1353/pew.0.0069

Priest, Graham. (2018a). Buddhist Dependence. In Ricki Bliss and Graham Priest (Eds.), Reality and its Structure: Essays in Fundamentality (pp. 126-139). New York: Oxford University Press. https://doi. org/10.1093/oso/9780198755630.003.0007

Priest, G. (2018b). The Fifth Corner of Four: An Essay on Buddhist Metaphysics and the Catușkoți. Oxford University Press. https://doi.org/10.1093/oso/9780198758716.001.0001

Thiele, L. P. (2011). Indra's Net and the Midas Touch: Living Sustainably in a Connected World. MIT Press.

Thompson, Naomi. (2016). Metaphysical Interdependence. In Mark Jago (Ed.), Reality Making (pp. 38-55). New York: Oxford University Press. https://doi.org/10.1093/acprof:oso/9780198755722. 003.0003

Turner, Jason. (2014). Donald Baxter's Composition as Identity. In A.J. Cotnoir and Donald L.M. Baxter (Eds.), Composition as Identity (pp. 225-243). New York: Oxford University Press. https://doi.org/ 10.1093/acprof:oso/9780199669615.003.0012

Van Norden, Bryan and Nicholaos Jones. (2019). Huayan Buddhism. The Stanford Encyclopedia of Philosophy (Winter 2019 Edition), Edward N. Zalta (ed.), https://plato.stanford.edu/archives/win2019/ entries/buddhism-huayan/.

Wang, R. R. (2005). Dong Zhongshu's Transformation of Yin-Yang Theory and Contesting of Gender Equality. Philosophy East and West, 55(2), 209-231. https://doi.org/10.1353/pew.2005.0013

Wang, R. R. (2015). Yinyang Narrative of Reality: Chinese Metaphysical Thinking. In C. Metaphysics \& I. Problems (Eds.), Chenyang Li and Franklin Perkins (pp. 16-32). Cambridge University Press.

Williamson, T. (2005). Contextualism, Subject-Sensitive Invariantism and Knowledge of Knowledge. The Philosophical Quarterly, 55(219), 213-235. https://doi.org/10.1111/j.0031-8094.2005.00396.x 